\title{
Review of Vehicle Surveillance Using Iot in the Smart Transportation Concept
}

\author{
Nur Kumala Dewi \\ STMIK Muhammadiyah Jakarta, Indonesia \\ Email: nkd.mandori@gmail.com
}

Received: 13 January 2021; Accepted: 28 January 2021; Published: 08 February 2021

\begin{abstract}
The background of this research raises the problem of the development of smart transportation in terms of monitoring and enforcement of traffic on the highway, with the proposed system that will help many parties such as the police and the government. The system that is running is to develop a system using CCTV that is placed on every corner of the capital city to replace the police in carrying out road surveillance and law enforcement against lawbreakers, especially in the traffic sector. The method used in this research is by using literature review of many previous research journals, by reading many journals will be able to add knowledge and can deepen ongoing research. The problem raised in this research is finding solutions to problems in the transportation sector, especially smart transportation, using smart transportation will be able to connect all systems that have been made. This research produces a system proposal that can be used in further research and can be applied in terms of the development of smart cities, especially smart transportation.
\end{abstract}

Index Terms: Vehicle, Internet of Think (IoT), Transportation, Violations.

\section{Introduction}

Transportation is one of the most important parts in a developing and developed city, the more advanced a city will have a sophisticated transportation system, with the transportation system connected to other parties, it will make it easier for people in their daily lives [1], for example with a digital payment system, so people don't You need to bring cash if you want to go by the transportation system, because you can pay using the QR Code system, so you can reduce transactions with banknotes that are easily damaged [2]. In Indonesia, the system that is running is to use CCTV in conducting surveillance and prosecution, CCTV is used because it can monitor traffic violations on the highway to the maximum, surveillance must be carried out even though there are no police on the road [3], therefore CCTV placement is many in every highway corner is an existing solution, with the existing system and the proposed system that is made it will make the system even better [4]. Now everything is related to the internet, almost all systems are connected to the internet, with the internet, data retrieval and data transmission will be much faster [5], so that data processing can be done immediately so that it can produce the desired data, with the internet, everything will be easy and Jakarta's smart city system will become more sophisticated [6].

The research method is carried out by conducting a literature review, by reading many books and journals, it will deepen a study and be able to find new problems that can be raised in a study [7], by reading will add to the writer's insight in conducting future research [8]. The problem that will be raised in this research is to find solutions in solving problems in the transportation sector, especially in the supervision and enforcement on the road which is usually carried out by the police, by using the system it will help the police [9].

This research produces a system proposal that can assist the police in monitoring and prosecuting traffic violations on the highway [10], with the suggestion that this system can be used as a basis for the government, namely the police in taking action through the system and becoming part of the smart transportation system [11].

\section{Literature Review}

Internet of Things (IoT) is one of the main pillars in the development of the Industrial revolution [12]. IoT has an impact on the manufacturing industry [13]. The results of research conducted by Hamzeh et al. in investigating the application of IoT for Small and Medium Enterprises (SMEs) to New Zealand's local manufacturing shows that Industry 4.0 with IoT can be the key to transforming and enhancing future SMEs with reference to a model that local companies can use to benefit from the Industry 4.0 concept [14]. 
Vehicle Classification (VC) is defined as a module used to classify vehicles into several different classifications [15]. Later, this will be useful for monitoring traffic flow, automatic parking systems, and others. In addition, VCs can provide vehicle information both physically and kinematically [16]. This information is then used as a source of data in the development of "smart vehicles". There are several levels of sophistication of smart vehicle automation systems, from non-automation to full automation [17]. Long before that, the conventional VC method was gradually developing [18].

Deepbus is machine learning to identify irregularities on the road surface in real time using IoT [19]. Inside the Deepbus, there is an IoT sensor to detect holes where the information will be distributed in real time and then display it on a map. There are millions of holes in the road that cause death and injury [19]. From that reason Deepbus was created. Deepbus helps road users to be aware of where potholes are located so as to reduce the risk of an accident and provide appropriate information to government and civil authorities to make repairs as quickly as possible [20].

There are many uses of deep learning itself [21]. With the population density increasing from year to year, it has resulted in many problems in the city. Infrastructure plays an important role in solving this problem [22]. By integrating deep learning techniques into the infrastructure intelligence model, it can monitor energy consumption, congestion levels, and can make decisions based on its level [23]. So that it can reduce the problems that exist in the city [24].

The concept of applying the internet of vehicle is to make vehicles run without a driver. vehicles can load sensory data, and choose the type of road environment and the chosen destination [25]. and prevention of pedestrian accidents. vehicles using the internet of vehicle can communicate with each other to determine the road and vehicle status in real time which is useful for estimating the average speed and identifying the optimal route to reach the destination [26].

Based on the literature reviewed above, most of the proposed IDS and MDS for smart vehicles ignore the dynamic nature of the networks these vehicles use to communicate with each other as well as the RSU [27]. Therefore, the data collected may not be representative enough to construct an accurate detection solution. Another limitation plagued by existing solutions is the assumption of an honest majority [28].

The algorithm is called ATDA (Adaptive Threshold Detection Algorithm) with a precision level of up to 97\%, but the classification scheme is inefficient and with low performance because the overall recognition rate is below 60\% [29]. Therefore, the authors complete a study that is almost the same as the title of this study by using MSVCA as a research method [30].

Smart transportation services in a city that applies information and communication technology are prioritized because they can develop a city towards a smart city, this is necessary so that the city of Jakarta becomes a more developed city [31].

The application of sophisticated equipment in traffic control to recognize vehicles has been widely applied to assist the police in monitoring and prosecuting traffic offenders on the highway [32].

A novel vehicle classification technique has been developed based on multiple pavement strains caused by moving traffic loads [33]. The overlap of vehicle classification feature parameters belonging to different classes suggested the need to use a pattern recognition technique for separating vehicles into different groups [34]. To improve classification accuracy and robustness centralized and distributed fusion schemes based on two popular SVMs multi-class algorithms were used as fusion multiple sensor data [35]. Comparison of experimental results shows the OAA and OAO methods with distributed fusion strategies are more suitable for practical use [36]. Smart transportation is one of the interesting things for IoT project developers, by using data taken from users, researchers or project developers are very interested in optimizing navigation and the best route for users so that it can provide various conveniences for users such as an overview of density . on the road, shorten the travel time, even the condition of the road surface taken from the user's vehicle input or other sensors [37]. With so many traces of data that can be taken, all of these can be processed using IoT and Machine Learning [38].

IoT allows us to process data sets accurately using a sensor based system. The higher the technology, the more threats such as in terms of security of an application [39]. Therefore, a decentralized application is needed which makes it possible to create an integrated multi-dimensional system and can thwart various threats because the system is not centralized, so that the system is distributed into several channels. To make this happen, it takes a dynamic token to complete each transaction. Dynamic token is a code that changes every time a transaction is made, it is different from static tokens such as regular passwords so that it is more secure [40].

\section{Development of Smart Transportation}

At this stage, it discusses the research methods used in this research, with this method the direction of the research becomes orderly and directed, as for the picture of the research method as follows: 


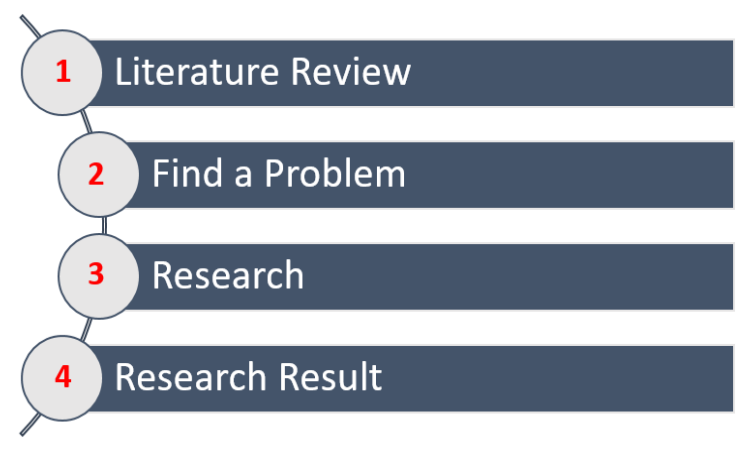

Fig. 1. Research Methods

Based on the image of the research method above, the following explanation will be given:

\section{A. Literature Review}

The first part in this stage of a research is to use a literature review, by reading many journals you will be able to deepen the knowledge of the research that is being raised [41], with a literature review you will be able to find new research problems [42].

\section{B. Find a Problem}

In the second stage by finding the research problem raised [43], the problem is that there is something basic of research on which to base the research, with the problem it will be able to find out what to find out in the problemsolving process [44].

\section{Research}

In the third part of this research is to do research in order to solve the research problem raised [45], by following the research method used will be able to solve the research problem, this stage is carried out step by step [46].

\section{Research Result}

The last part is the part of this research that has been able to answer the problems raised, and produces the results of the journal review reviews discussed in this study [47].

ILDs are usually employed in traffic management systems to estimate vehicle parameters such as speed and length. These ILDs use a reference clock signal whose frequency is of several MHz, typically between 20 and 1000 times greater than the oscillation frequency of the inductive loop we are employing for measurement [48]. When a vehicle stops or passes over the loop the oscillation frequency increases, so the period decreases. This parameter $\Delta \mathrm{T}$ gives us the amplitude of the vehicle inductive signature at a time instant [49]. Acceleration of the vehicle will cause the wheelbase to seem smaller [50], While deceleration will cause the wheelbase to seem larger according to the classification system. Classification depends mostly on the accuracy in estimating the speed. The following data was obtained this vehicle with different speeds repeated 10 times [51]. In a smart city, the IoT application is divided into several categories, namely smart homes, health-care assistance, smart transportation, environmental conditions monitoring, logistics and supply chain management, and security and surveillance systems [52]. The number of sophisticated technologies makes us use smart devices and gadgets to do a bunch of jobs. With the emergence of demand for high-level services in various sectors, conventional methods and techniques must shift to smart technologies such as the Internet of Things (IoT), Internet of Everything (IoE), and Internet of Vehicles (IoV) [53]. To test the feasibility of using the traffic mobility information data for delinquency detection, the delinquency detection model uses Artificial Neural Networks [54]. The test dataset is further divided into two subsets T1 and T2., In our implementation only some of the values in the following attributes have been falsified making it difficult for the detection model to distinguish between truth data and falsified data [55]. This is due to the evasion approach that attackers use to carry out advanced and sophisticated bad-behavior attacks, which make it difficult for these machine learning algorithms to distinguish between normal and bad-behaved nodes [56].

\section{Proposed System in Smart Transportation}

The transportation system is divided into three, namely land transportation, sea transportation and air transportation [57]. In this study, it will discuss how the supervision of land transportation, especially in the field of traffic, will be made into a system that will make it easier for the police to supervise and take action on the highway [58]. With the proposed smart system this time, a synergy will be created for all parties connected to the transportation 
sector, especially land transportation, for example the Department to the relationship between the police and the Jakarta Raya traffic service, with all systems being connected, it will be able to help all parties and be able to help the community. in driving on the highway [59].

This section discusses the system that will be proposed in this paper, below is a picture and explanation [60].

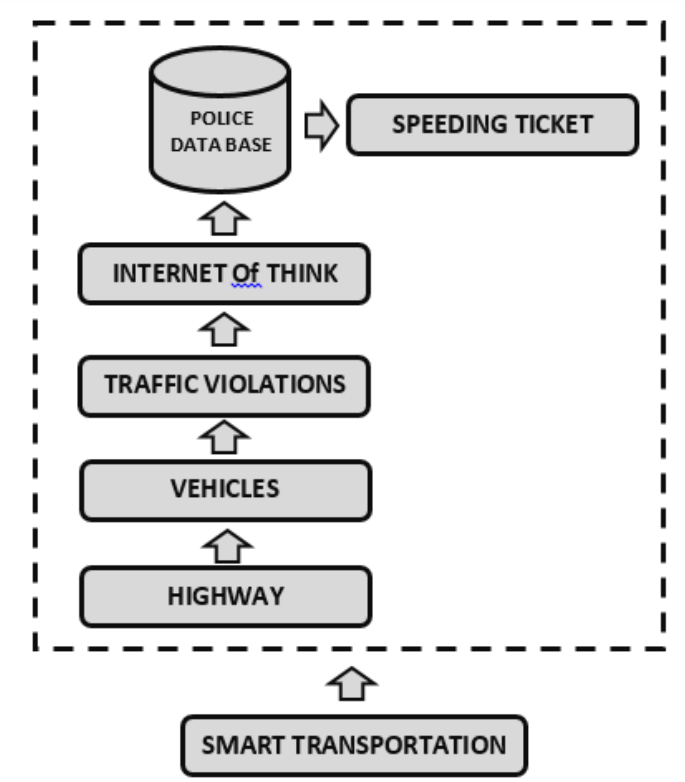

Fig. 2. System will be Proposed

Based on the picture above, the following explanation will be given:

\section{A. Speeding Ticket}

A ticket is given because the driver has committed an offense on the highway [61], by getting a ticket and getting a penalty in the form of a fine, it is hoped that the offending driver will feel guilty and will not repeat it again [62].

\section{B. Police Data Base}

The police data base is a place to store all violations that have been committed by motorists [63], with a data base the data will be neatly arranged and if one day it is needed it will be found quickly, accurate data will produce reliable data [64].

\section{Internet of Think}

Internet of Think is the medium used in sending data to the police database [65], with Internet og Think the process of recording and prosecution will be faster and can be processed immediately [66].

\section{Traffic Violations}

Traffic violations occur because drivers violate regulations that have been made, for example violating road markings, running red lights, and many other violations, traffic violations must be avoided because they will result in a ticket [67].

\section{E. Vehicles}

A motorized vehicle is a tool used in driving, some are 2-wheeled and 4-wheeled, and it could be more, by driving a vehicle, the driver must follow the rules that have been made, for example the completeness of a driving certificate, and all traffic signs on the road, if you violate will be subject to penalty penalties [68].

\section{F. Higway}

The highway is a place for motorized 2 and 4-wheeled vehicles to run and there are riders who commit violations, by committing violations on the highway they will be immediately punished [69]. 


\section{G. Smart Transportation}

Intelligent transportation is one that is connected to a system that can do things like humans, for example surveillance such as CCTV and enforcement such as E-TLE, there are many more systems that are made to help humans in many ways, because humans have limitations, so with an intelligent transportation system then you will be able to supervise the highway 24 hours meaning a full day without stopping [70].

Based on the picture and explanation above, we can conclude that smart transportation on land transportation which is proposed by the system will use internet media as a medium for sending data to and from the database with the internet media, all data processing will be carried out quickly so that action against violations on the highway will can be done immediately without having to wait for the time so everything can be done quickly [71].

Based on the above proposed system, it can be concluded below

\section{Conclusion}

Based on the results of the above research, the authors draw the following conclusions. The application of intelligent transportation using internet media for vehicle surveillance on the road is very effective and very helpful for the authorities, namely the police in conducting surveillance and prosecution, with internet media, data will be sent quickly to the data base and action can be carried out as soon as possible, and with issue electronic ticketing for those who commit violations. Future research by applying sensor technology in data collection in the field, with sensors will make it easier to identify violations that have been committed by motorized vehicle drivers.

\section{References}

[1] Y. Agarwal, K. Jain, and O. Karabasoglu, "Smart vehicle monitoring and assistance using cloud computing in vehicular Ad Hoc networks," Int. J. Transp. Sci. Technol., vol. 7, no. 1, pp. 60-73, 2018, doi: 10.1016/j.ijtst.2017.12.001.

[2] M. Agbali, C. Trillo, T. Fernando, I. A. Ibrahim, and Y. Arayici, "Conceptual Smart City KPI Model: A System Dynamics Modelling Approach," Proc. 2nd World Conf. Smart Trends Syst. Secur. Sustain. WorldS4 2018, pp. 158-162, 2019, doi: 10.1109/WorldS4.2018.8611565.

[3] S. H. Ahmed, M. A. Yaqub, S. H. Bouk, and D. Kim, "Towards content-centric traffic ticketing in VANETs: An application perspective," Int. Conf. Ubiquitous Futur. Networks, ICUFN, vol. 2015-Augus, pp. 237-239, 2015, doi: 10.1109/ICUFN.2015.7182541.

[4] G. Aisyah and P. Bestari, "Implementation E-Tilang in Bandung to Increase Awareness of Cross as Moral Law Passed Citizenship (Civic Virtue)," vol. 251, no. 22, pp. 664-667, 2018, doi: 10.2991/acec-18.2018.148.

[5] Z. Al-Ars, S. van der Vlugt, P. Jääskeläinen, and F. van der Linden, "ALMARVI System Solution for Image and Video Processing in Healthcare, Surveillance and Mobile Applications," J. Signal Process. Syst., vol. 91, no. 1, pp. 1-7, 2019, doi: 10.1007/s11265-018-1423-2.

[6] Z. Allam and P. Newman, "Redefining the Smart City: Culture, Metabolism and Governance," Smart Cities, vol. 1, no. 1, pp. 4-25, 2018, doi: 10.3390/smartcities1010002.

[7] A. S. Putra and F. R. Radita, "Paradigma Belajar Mengaji Secara Online Pada Masa Pandemic Coronavirus Disease 2019

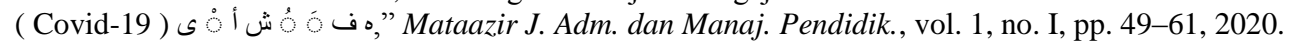

[8] B. A. Alpatov, P. V. Babayan, and M. D. Ershov, "Vehicle detection and counting system for real-time traffic surveillance," 2018 7th Mediterr. Conf. Embed. Comput. MECO 2018 - Incl. ECYPS 2018, Proc., no. June, pp. 1-4, 2018, doi: 10.1109/MECO.2018.8406017.

[9] A. A. Ambardekar and T. Advisor, "Efficient Vehicle Tracking and Classification for an Automated Traffic Surveillance System," 2007.

[10] H. Lisnawati and A. Sinaga, "Data mining with associated methods to predict consumer purchasing patterns," Int. J. Mod. Educ. Comput. Sci., vol. 12, no. 5, pp. 16-28, 2020, doi: 10.5815/ijmecs.2020.05.02.

[11] M. Mitra and A. Chowdhury, "A modernized voting system using fuzzy logic and blockchain technology," Int. J. Mod. Educ. Comput. Sci., vol. 12, no. 3, pp. 17-25, 2020, doi: 10.5815/ijmecs.2020.03.03.

[12] Muhammad Syarif Hartawan, Arman Syah Putra, and Ayub Muktiono, "Smart City Concept for Integrated Citizen Information Smart Card or ICISC in DKI Jakarta," Int. J. Sci. Technol. Manag., vol. 1, no. 4, pp. 364-370, 2020, doi: 10.46729/ijstm.v1i4.76.

[13] N. K. Dewi et al., "Konsep Aplikasi E-Dakwah Untuk Generasi Milenial Jakarta penting dalam menyiarkan agama Islam . Dengan media dakwah yang tepat maka akan bisa menyiarkan agama Islam dengan maksimal dengan media dakwah yang tepat suatu konsep dalam berdakwah dengan E-Dakwa," vol. 5, no. 2, pp. 26-33, 2021.

[14] N. K. Dewi, I. Mulyana, A. S. Putra, and F. R. Radita, "Tampilan Konsep Robot Penjaga Toko Di Kombinasikan Dengan Pengendalian Virtual Reality (VR) Jarak Jauh,” J. IKRA-ITH Inform., vol. 5, no. 1, pp. 33-38, 2021, [Online]. Available: https://journals.upi-yai.ac.id/index.php/ikraith-informatika/article/view/911/702.

[15] N. K. Dewi and A. S. Putra, "PENERIMAAN KARYAWAN BARU DENGAN," vol. 6, no. 2, pp. 154-160, 2020.

[16] S. Sathasivam, S. A. Alzaeemi, and M. Velavan, "Mean-field theory in hopfield neural network for doing 2 satisfiability logic programming," Int. J. Mod. Educ. Comput. Sci., vol. 12, no. 4, pp. 27-39, 2020, doi: 10.5815/ijmecs.2020.04.03.

[17] I. Ramadhan, A. Kurniawan, and A. S. Putra, "Penentuan Pola Penindakan Pelanggaran Lalu Lintas di DKI Jakarta Menggunakan Metode Analytic Network Process ( ANP )," vol. 5, no. 1, pp. 51-57. 
[18] P. Cardullo and R. Kitchin, "Being a 'citizen' in the smart city: up and down the scaffold of smart citizen participation in Dublin, Ireland,” GeoJournal, vol. 84, no. 1, 2019, doi: 10.1007/s10708-018-9845-8.

[19] J. Chang, L. Wang, G. Meng, S. Xiang, and C. Pan, "Vision-based occlusion handling and vehicle classification for traffic surveillance systems," IEEE Intell. Transp. Syst. Mag., vol. 10, no. 2, pp. 80-92, 2018, doi: 10.1109/MITS.2018.2806619.

[20] S. Chaudhuri and U. Dayal, "An Overview of Data Warehousing and OLAP Technology," SIGMOD Rec. (ACM Spec. Interes. Gr. Manag. Data), vol. 26, no. 1, pp. 65-74, 1997, doi: 10.1145/248603.248616.

[21] T. Regulations, P. P. Data, P. Examiner, and A. M. Au, “( 12 ) United States Patent,” vol. 2, no. 12, 2003.

[22] A. Pongpunwattana and R. Rysdyk, "Real-time planning for multiple autonomous vehicles in dynamic uncertain environments," J. Aerosp. Comput. Inf. Commun., vol. 1, no. DEC., pp. 580-604, 2004, doi: 10.2514/1.12919.

[23] P. Polack, F. Altche, B. DAndrea-Novel, and A. De La Fortelle, "The kinematic bicycle model: A consistent model for planning feasible trajectories for autonomous vehicles?," IEEE Intell. Veh. Symp. Proc., no. Iv, pp. 812-818, 2017, doi: 10.1109/IVS.2017.7995816.

[24] S. Chaudhuri and U. Dayal, "Data warehousing and OLAP for decision support," Lect. Notes Comput. Sci. (including Subser. Lect. Notes Artif. Intell. Lect. Notes Bioinformatics), vol. 1341, pp. 33-34, 1997, doi: 10.1007/3-540-63792-3_6.

[25] J. W. Choi, R. Curry, and G. Elkaim, "Path planning based on bézier curve for autonomous ground vehicles," Proc. - Adv. Electr. Electron. Eng. - IAENG Spec. Ed. World Congr. Eng. Comput. Sci. 2008, WCECS 2008, no. 2, pp. 158-166, 2008, doi: 10.1109/WCECS.2008.27.

[26] G. Corraro, F. Corraro, E. De Lellis, and L. Garbarino, "Flight tests of ADS-B traffic advisory system (ATAS) and performance comparison with other surveillance systems," AIAA Aerosp. Sci. Meet. 2018, no. 210059, 2018, doi: 10.2514/6.2018-0286.

[27] R. Cowley, S. Joss, and Y. Dayot, "The smart city and its publics: insights from across six UK cities," Urban Res. Pract., vol. 11, no. 1, pp. 53-77, 2018, doi: 10.1080/17535069.2017.1293150.

[28] M. Desai and A. Phadke, "Internet of Things based vehicle monitoring system," IFIP Int. Conf. Wirel. Opt. Commun. Networks, WOCN, pp. 1-3, 2017, doi: 10.1109/WOCN.2017.8065840.

[29] M. A. Elliott, C. J. Baughan, and B. F. Sexton, "Errors and violations in relation to motorcyclists' crash risk," Accid. Anal. Prev., vol. 39, no. 3, pp. 491-499, 2007, doi: 10.1016/j.aap.2006.08.012.

[30] J. Gao and H. Tembine, "Distributed Mean-Field-Type Filters for Traffic Networks," IEEE Trans. Intell. Transp. Syst., vol. 20, no. 2, pp. 507-521, 2019, doi: 10.1109/TITS.2018.2816811.

[31] B. Garau, A. Alvarez, and G. Oliver, "Path planning of autonomous underwater vehicles in current fields with complex spatial variability: An A* approach,” Proc. - IEEE Int. Conf. Robot. Autom., vol. 2005, no. April, pp. 194-198, 2005, doi: 10.1109/ROBOT.2005.1570118.

[32] K. Garg, N. Ramakrishnan, A. Prakash, and T. Srikanthan, "Rapid and Robust Background Modeling Technique for Low-Cost Road Traffic Surveillance Systems," IEEE Trans. Intell. Transp. Syst., vol. 21, no. 5, pp. 2204-2215, 2020, doi: 10.1109/TITS.2019.2917560.

[33] R. B. Pendor and P. P. Tasgaonkar, "An IoT framework for intelligent vehicle monitoring system,” Int. Conf. Commun. Signal Process. ICCSP 2016, pp. 1694-1696, 2016, doi: 10.1109/ICCSP.2016.7754454.

[34] P. Giannakeris, V. Kaltsa, K. Avgerinakis, A. Briassouli, S. Vrochidis, and I. Kompatsiaris, "Speed estimation and abnormality detection from surveillance cameras," IEEE Comput. Soc. Conf. Comput. Vis. Pattern Recognit. Work., vol. 2018-June, pp. 9399, 2018, doi: 10.1109/CVPRW.2018.00020.

[35] S. Pohlmann and U. Traenkle, "Orientation in road traffic. Age-related differences using an in-vehicle navigation system and a conventional map,” Accid. Anal. Prev., vol. 26, no. 6, pp. 689-702, 1994, doi: 10.1016/0001-4575(94)90048-5.

[36] M. G. Gnoni, A. Rollo, and P. Tundo, "A smart model for urban ticketing based on RFID applications," IEEM 2009 - IEEE Int. Conf. Ind. Eng. Eng. Manag., pp. 2353-2357, 2009, doi: 10.1109/IEEM.2009.5373004.

[37] R. J. Reisman, "Air traffic management blockchain infrastructure for security, authentication, and privacy," AIAA Scitech 2019 Forum, pp. 1-14, 2019, doi: 10.2514/6.2019-2203.

[38] E. Guerra, "Planning for Cars That Drive Themselves: Metropolitan Planning Organizations, Regional Transportation Plans, and Autonomous Vehicles," J. Plan. Educ. Res., vol. 36, no. 2, pp. 210-224, 2016, doi: 10.1177/0739456X15613591.

[39] G. Guido, V. Gallelli, D. Rogano, and A. Vitale, "Evaluating the accuracy of vehicle tracking data obtained from Unmanned Aerial Vehicles,” Int. J. Transp. Sci. Technol., vol. 5, no. 3, pp. 136-151, 2016, doi: 10.1016/j.ijtst.2016.12.001.

[40] G. Guido, A. Vitale, F. F. Saccomanno, V. Astarita, and V. Giofrè, "Vehicle Tracking System based on Videotaping Data," Procedia - Soc. Behav. Sci., vol. 111, pp. 1123-1132, 2014, doi: 10.1016/j.sbspro.2014.01.147.

[41] S. Parekh, N. Dhami, S. Patel, and J. Undavia, "Traffic signal automation through iot by sensing and detecting traffic intensity through ir sensors," Smart Innov. Syst. Technol., vol. 106, pp. 53-65, 2019, doi: 10.1007/978-981-13-1742-2_6.

[42] H. Gunawan and Lynawati, "Analisis Penerimaan Teknologi 'Smart City' Kota Purwokerto Dengan Model Technology Acceptance Model (TAM)," Konf. Nas. Sist. Inf., pp. 129-134, 2018, [Online]. Available: http://jurnal.atmaluhur.ac.id/index.php/knsi2018/article/view/347/272.

[43] D. Parker, J. T. Reason, A. S. R. Manstead, and S. G. Stradling, "Driving errors, driving violations and accident involvement," Ergonomics, vol. 38, no. 5, pp. 1036-1048, 1995, doi: 10.1080/00140139508925170.

[44] C. El Hatri and J. Boumhidi, "Fuzzy deep learning based urban traffic incident detection," 2017 Intell. Syst. Comput. Vision, ISCV 2017, 2017, doi: 10.1109/ISACV.2017.8054903.

[45] S. D. Pendleton et al., "Perception, planning, control, and coordination for autonomous vehicles," Machines, vol. 5, no. 1, pp. 1-54, 2017, doi: 10.3390/machines5010006.

[46] J. Z. Hernández, S. Ossowski, and A. García-Serrano, "Multiagent architectures for intelligent traffic management systems," Transp. Res. Part C Emerg. Technol., vol. 10, no. 5-6, pp. 473-506, 2002, doi: 10.1016/S0968-090X(02)00032-3.

[47] J. I. Hernández-Vega, E. R. Varela, N. H. Romero, C. Hernández-Santos, J. L. S. Cuevas, and D. G. P. Gorham, Internet of things (IoT) for monitoring air pollutants with an unmanned aerial vehicle (UAV) in a smart city, vol. 213. Springer International Publishing, 2018. 
[48] G. T. S. Ho, Y. P. Tsang, C. H. Wu, W. H. Wong, and K. L. Choy, "A computer vision-based roadside occupation surveillance system for intelligent transport in smart cities,” Sensors (Switzerland), vol. 19, no. 8, 2019, doi: 10.3390/s19081796.

[49] Y. Huang, Z. Liu, M. Jiang, X. Yu, and X. Ding, "Cost-Effective Vehicle Type Recognition in Surveillance Images with Deep Active Learning and Web Data," IEEE Trans. Intell. Transp. Syst., vol. 21, no. 1, pp. 79-86, 2020, doi: 10.1109/TITS.2018.2888698.

[50] N. K. Jain, R. K. Saini, and P. Mittal, A review on traffic monitoring system techniques, vol. 742. Springer Singapore, 2019.

[51] José Miguel Cisneros Herreros and Germán Peñalva Moreno, “Article in Press Article in Press," GEF Bull. Biosci., vol. 1, no. 1, pp. 1-6, 2010, doi: 10.1016/j.jinf.2020.02.020.

[52] R. Kala and K. Warwick, "Motion planning of autonomous vehicles in a non-autonomous vehicle environment without speed lanes," Eng. Appl. Artif. Intell., vol. 26, no. 5-6, pp. 1588-1601, 2013, doi: 10.1016/j.engappai.2013.02.001.

[53] Kenny, "United States Patent (19) 11 Patent Number: 5,348,136," no. 19, pp. 1992-1995, 1993.

[54] B. Nemade, "Automatic Traffic Surveillance Using Video Tracking," Procedia Comput. Sci., vol. 79, pp. 402-409, 2016, doi: 10.1016/j.procs.2016.03.052.

[55] H. J. Kim, "Vehicle detection and speed estimation for automated traffic surveillance systems at nighttime," Teh. Vjesn., vol. 26, no. 1, pp. 87-94, 2019, doi: 10.17559/TV-20170827091448.

[56] K. J. Kim, P. K. Kim, Y. S. Chung, and D. H. Choi, "Multi-Scale Detector for Accurate Vehicle Detection in Traffic Surveillance Data," IEEE Access, vol. 7, pp. 78311-78319, 2019, doi: 10.1109/ACCESS.2019.2922479.

[57] S. W. Kim, W. Liu, M. H. Ang, E. Frazzoli, and D. Rus, "The Impact of Cooperative Perception on Decision Making and Planning of Autonomous Vehicles," IEEE Intell. Transp. Syst. Mag., vol. 7, no. 3, pp. 39-50, 2015, doi: 10.1109/MITS.2015.2409883.

[58] T. Kumar and D. S. Kushwaha, "An intelligent surveillance system based on IoT for internal security of a nation," Int. J. Inf. Secur. Priv., vol. 13, no. 3, pp. 1-30, 2019, doi: 10.4018/IJISP.201907010101.

[59] X. Li, J. Niu, S. Kumari, F. Wu, and K. K. R. Choo, "A robust biometrics based three-factor authentication scheme for Global Mobility Networks in smart city," Futur. Gener. Comput. Syst., vol. 83, pp. 607-618, 2018, doi: 10.1016/j.future.2017.04.012.

[60] M. Likhachev and D. Ferguson, "Planning long dynamically-feasible maneuvers for autonomous vehicles," Robot. Sci. Syst., vol. 4, pp. 214-221, 2009, doi: 10.15607/rss.2008.iv.028.

[61] V. Murugan, V. R. Vijaykumar, and A. Nidhila, "A deep learning RcNn approach for vehicle recognition in traffic surveillance system," Proc. 2019 IEEE Int. Conf. Commun. Signal Process. ICCSP 2019, pp. 157-160, 2019, doi: 10.1109/ICCSP.2019.8698018.

[62] M. Lu et al., "Cooperative and connected intelligent transport systems for sustainable European road transport Citation for published version (APA): Cooperative and Connected Intelligent Transport Systems for Sustainable European Road Transport," no. 2018, 2018, [Online]. Available: www.tue.n1/taverne.

[63] P. G. V. Naranjo, Z. Pooranian, M. Shojafar, M. Conti, and R. Buyya, "FOCAN: A Fog-supported smart city network architecture for management of applications in the Internet of Everything environments," J. Parallel Distrib. Comput., vol. 132, pp. 274-283, 2019, doi: 10.1016/j.jpdc.2018.07.003.

[64] Z. Lv, X. Li, W. Wang, B. Zhang, J. Hu, and S. Feng, "Government affairs service platform for smart city," Futur. Gener. Comput. Syst., vol. 81, pp. 443-451, 2018, doi: 10.1016/j.future.2017.08.047.

[65] K. Nellore and G. P. Hancke, "A survey on urban traffic management system using wireless sensor networks," Sensors (Switzerland), vol. 16, no. 2, 2016, doi: 10.3390/s16020157.

[66] S. Lyu et al., "UA-DETRAC 2018: Report of AVSS2018 IWT4S Challenge on Advanced Traffic Monitoring," Proc. AVSS 2018 - 2018 15th IEEE Int. Conf. Adv. Video Signal-Based Surveill., pp. 1-7, 2019, doi: 10.1109/AVSS.2018.8639089.

[67] V. C. Maha Vishnu, M. Rajalakshmi, and R. Nedunchezhian, "Intelligent traffic video surveillance and accident detection system with dynamic traffic signal control," Cluster Comput., vol. 21, no. 1, pp. 135-147, 2018, doi: 10.1007/s10586-0170974-5.

[68] V. A. Memos, K. E. Psannis, Y. Ishibashi, B. G. Kim, and B. B. Gupta, "An Efficient Algorithm for Media-based Surveillance System (EAMSuS) in IoT Smart City Framework,” Futur. Gener. Comput. Syst., vol. 83, no. 2018, pp. 619-628, 2018, doi: 10.1016/j.future.2017.04.039.

[69] A. Mhalla, T. Chateau, S. Gazzah, and N. E. Ben Amara, "An Embedded Computer-Vision System for Multi-Object Detection in Traffic Surveillance," IEEE Trans. Intell. Transp. Syst., vol. 20, no. 11, pp. 4006-4018, 2019, doi: 10.1109/TITS.2018.2876614.

[70] J. S. B. Mitchell, D. W. Payton, and D. M. Keirsey, "Planning and reasoning for autonomous vehicle control," Int. J. Intell. Syst., vol. 2, no. 2, pp. 129-198, 1987, doi: 10.1002/int.4550020204.

[71] A. Murtaza, S. J. Hussain Pirzada, L. Jianwei, and T. Xu, "Air traffic surveillance using IP-Based space information network," 2019 28th Wirel. Opt. Commun. Conf. WOCC 2019 - Proc., no. May, 2019, doi: 10.1109/WOCC.2019.8770697.

\section{Author's Profile}

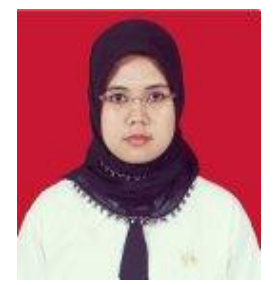

Nur Kumala Dewi born in Jombang December 20, 1980. Is the first daughter of two children of Mr. H. Achmad Karim Sueb and Mrs. Hj. Masbenul Karimah. Completing education at Madrasah Ibtidaiyah Educational Foundation (MI YASPIN), Junior High School of the Indonesian Education Foundation (SMP YANINDO) North Jakarta, SMUN 40 North Jakarta. In 2003 completed his undergraduate study (S1) at the Faculty of Computer Science, Universitas Pembangunan Nasional 'Veteran' Jakarta. In 2008, Graduated with Masters in Education Management at the State University of Jakarta (UNJ) and in 2014 completed the Doctor of Education Management Study Program at UNJ.

Recorded from 1997 to 2007 as a Teacher in the Field of English Studies at YANINDO Junior High 
School, YANINDO Senior High School (SMEA), Madrasah Aliyah Al Jihad. Lecturer in English and Research Methodology at STMIK Muhammadiyah Jakarta. Owner of Warung Bebek Volker H. Sueb Restaurant since 1987 in North Jakarta, Commissioner of PT. Boilerindo Karya Perkasa Jakarta and Civil Servants (PNS) at the Ministry of Religion of the Republic of Indonesia as Head of the Islamic Religious Broadcast Section of the Directorate of Information on Islamic Religion, Directorate General of Islamic Community Guidance (Ditjen Bimas Islam).

Married to Agus Mandori, ST., MM President Director of PT. Boilerindo Karya Perkasa Jakarta and blessed with one daughter and three sons, namely: Putri Balqiest Mandori is 15 years old, an eleventh grade student (XI) at MAN 3 Tambak Beras Jombang, East Java, Salman Alfarisy Mandori is a 10 year old fourth grade student (IV) in SDIT Al Amanah, Achmad Al Gazhali Mandori is 5 years old and Achmad Alfatih Mandori is 3 years old.

How to cite this paper: Nur Kumala Dewi, " Review of Vehicle Surveillance Using Iot in the Smart Transportation Concept ", International Journal of Engineering and Manufacturing (IJEM), Vol.11, No.1, pp. 29-36, 2021. DOI: 10.5815/ijem.2021.01.04 